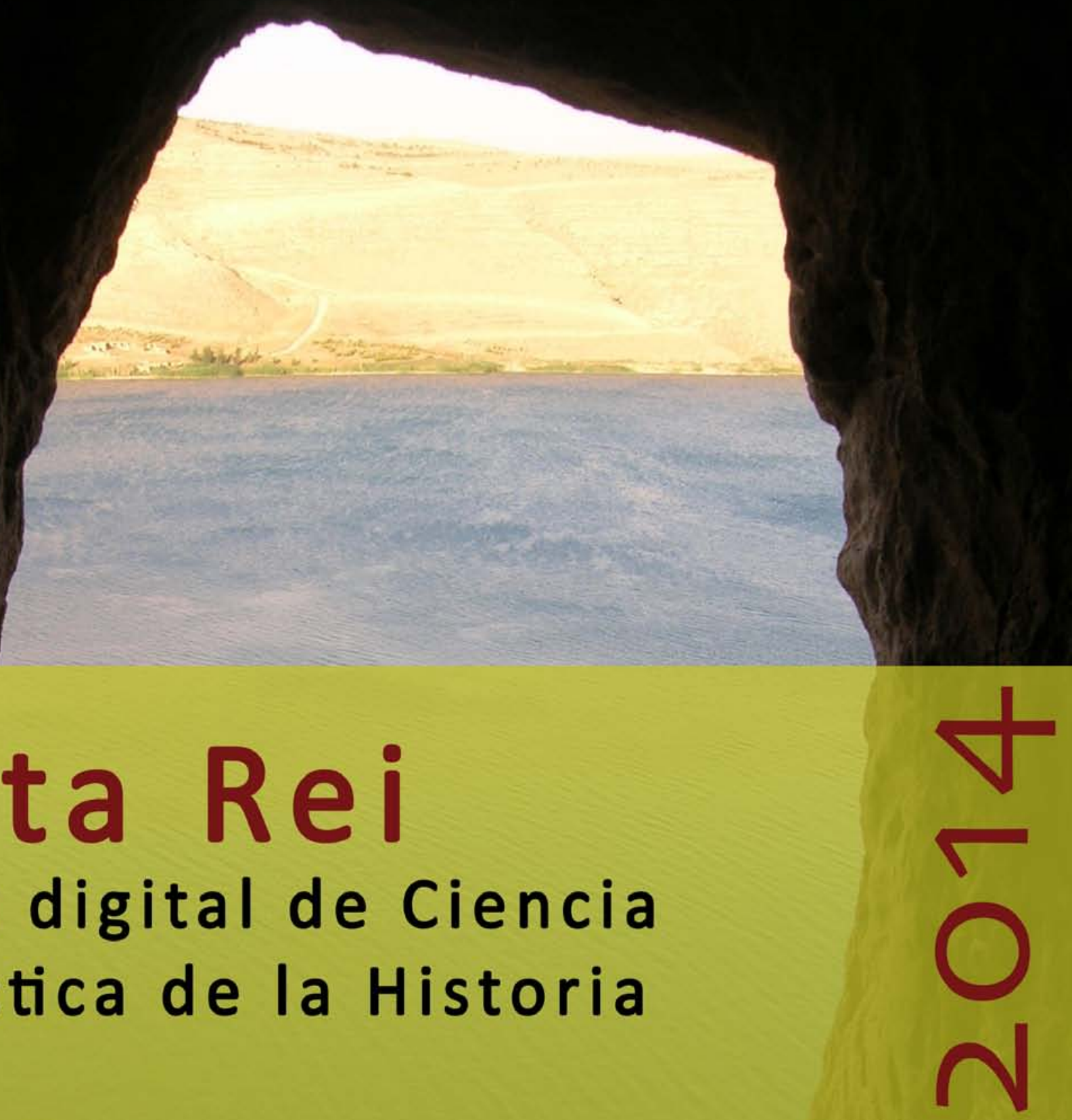





\section{Panta

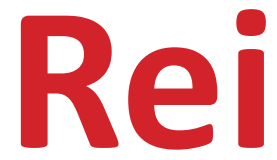 \\ Revista Digital de Ciencia \\ y Didáctica de la Historia}

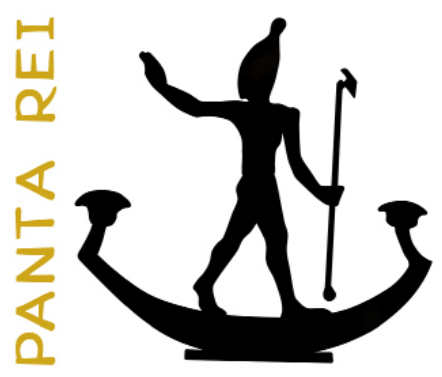

2014

Revista anual

Fecha de inicio: 1995

Revista Panta Rei. pantarei@um.es

\section{Edita:}

Centro de Estudios del Próximo Oriente y la

Antigüedad Tardía - CEPOAT

Edificio Universitario Saavedra Fajardo.

Universidad de Murcia

C/ Actor Isidoro Máiquez, 9

30007 - MURCIA - ESPAÑA

Teléfono: (+34) 868883890

cepoat@um.es

Web: www.um.es/cepoat/pantarei

Edición 2014

ISSNe: 2386-8864

ISSN: $1136-2464$

Depósito legal: MU-966-1995
cepoAt

UNIVERSIDAD DE MURCIA centro de estudios del próximo oriente y la antigüedad tardia

En Portada: Río Éufrates desde un eremitorio cristiano primitivo (Fotografía de Alejandro Egea).

Responsables de los textos:

Sus autores.

Responsable de la presente edición: Consejo Editorial Panta Rei. 


\section{CONSEJO DE REDACCIÓN}

\section{Coordinador editorial}

Egea Vivancos, Alejandro

[Didáctica de las Ciencias Sociales, UMU]

\section{Editores}

Botí Hernández, Juan Jesús

[CEPOAT, UMU]

Sáez Giménez, David Omar [CEPOAT, UMU]

\section{Secretaria}

Arias Ferrer, Laura

[Didáctica de las Ciencias Sociales, UMU]

\section{Responsable informático}

Martínez García, José Javier

[CEPOAT, UMU]

\section{Traducción y corrección lingüística}

Martínez Martínez, Cristina

[Sociedad Española de Lenguas Modernas]

\section{CONSEJO ASESOR}

Albero Muñoz, M. ${ }^{a}$ del Mar [H. ${ }^{a}$ del Arte, UMU]

Cobacho López, Ángel

[Derecho, UMU]

Egea Bruno, Pedro M. ${ }^{a}$

[Historia Contemporánea, UMU]

García Atienzar, Gabriel

[Prehistoria, UA]

González Monfort, Neus

[Didáctica de las Ciencias Sociales, UAB]

Haber Uriarte, María

[Prehistoria, UMU]

Irigoyen López, Antonio

[Historia Moderna, UMU]

Mahony, Simon

[Digital Humanities, UCL, Reino Unido]

Marsilla de Pascual, Francisco Reyes

[Técnicas historiográficas, UMU]

Miralles Maldonado, José Carlos

[Filología Clásica, UMU]

Molina Gómez, José Antonio

[Historia Antigua, UMU]

Noguera Celdrán, José Miguel

[Arqueología, UMU]

Pérez Molina, Miguel Emilio

[Filología Clásica, UMU]

Prados Martínez, Fernando

[Arqueología, UA]

Sánchez Ibáñez, Raquel

[Didáctica de las Ciencias Sociales, UMU]

Sancho Gómez, Miguel Pablo

[Educación, UCAM]

Vilar García, María José

[Historia Contemporánea, UMU] 
Presentación

Todo fluye. Renovarse y crecer

Alejandro Egea Vivancos, Laura Arias Ferrer, Juan Jesús Botí Hernández y David Omar Sáez Giménez

Artículos

La sociedad hiperbórea: ¿utopía o mito? Reflexiones acerca de la naturaleza y significado del relato hiperbóreo.

José Ángel Castillo Lozano.

Aproximación a la figura de una matrona romana culta y poderosa. El caso de Julia Domna.

Consuelo Isabel Caravaca Guerrero.

¡Arrasar la Vendée! Guerra Civil y Columnas Infernales en pleno corazón de la Revolución Francesa.

Benjamín Cutillas Victoria.....

Arte y expresión en el pensamiento de E. H. Gombrich.

Patricia Castiñeyra Fernández.

Odiseo a través de la parodia. Desmitificación e ironía de una Ítaca nostálgica en Prometeo de Pérez de Ayala y ¿Por qué corres, Ulises? de Gala.

Carmen María López López.

Análisis de la actividad didáctica del Museo de Arte Ibérico El Cigarralejo (Mula, Murcia).

Julio García Toral......

La Transición española en $4 .^{\circ}$ ESO. Un estudio de caso de los significados.

Borja Santiago Arnoso.

Entrevista

Entrevista al profesor D. Michael Walker.

Consuelo Isabel Caravaca Guerrero.

Reseñas

II Congreso de la Asociación Internacional de Investigación para la Educación de la Historia y las Ciencias Sociales.

Elvira Barriga y Rodrigo Salazar.

I Congreso de Jóvenes Investigadores del Mundo Antiguo de la Universidad de Murcia.

Pedro David Conesa Navarro

II Congreso Internacional de Educación Patrimonial.

Tània Martínez Gil.....

Ruiz-Gálvez Pliego, M. (2013). Con el fenicio en los talones. Los inicios de la Edad del Hierro en la cuenca del Mediterráneo. Barcelona: Editorial Bellaterra. 377 págs.

Celso Sánchez Mondéjar..

Normas de publicación/Publishing rules 



\title{
Aproximación a la figura de una matrona romana culta y poderosa. El caso de Julia Domna
}

\author{
Approach to the figure of a cultured and powerful Roman matron. The \\ case of Julia Domna
}

\author{
Consuelo Isabel Caravaca Guerrero \\ Universidad de Murcia
}

Recibido: 03/04/2014

Aceptado: $27 / 06 / 2014$

Para citar este artículo: Caravaca Guerrero, C. I. (2014). Aproximación a la figura de una matrona romana cultra y poderosa. El caso de Julia Domna. Panta Rei. Revista Digital de Ciencia y Didáctica de la Historia, 25-37.

ISSNe: 2386-8864

DOI: http://dx.doi.org/10.6018/pantarei/2014/3

\begin{abstract}
Resumen
El propósito de este trabajo es realizar una síntesis de las fuentes primarias que hablan de Julia Domna - destacando a Dión Casio, Herodiano, Historia Augusta y Flavio Filóstrato - y los estudios modernos principales, con el objetivo de conocer el papel e influencia que debió de ejercer esta mujer. Su papel no solo se basó en ser matrona, sino que consiguió ser esposa y madre de emperadores. Honrada con numerosos adjetivos como Augusta, Pía, Felix o mater Augustorum y mater castrorum, su influencia se extendió por todo el Imperio. Nos encontramos así, ante una figura que se salió de los márgenes impuestos por la sociedad romana a las mujeres.
\end{abstract}

\section{Palabras clave}

Julia Domna, Roma, matrona, política, dinastía Severa.

\section{Abstract}

This work is aimed to do a synthesis of every primary source that speaks about Julia Domna specially Dion Casio, Herodiano, Historia Augusta and Flavio Filostrato - as well as the main modern studies, with the objective of knowing the role and influence this woman might have exercised. Her role was not only based on the fact she was a midwife, but she also managed to be a wife and an emperor's mother. Honoured with several adjectives such as Augusta, Pía, Felix or mater Augustorum and mater castrorum, her influence spread all over the Empire. Therefore, we are dealing with a figure that went out from the margins imposed to women by the Roman society.

\section{Keywords}

Julia Domna, Rome, midwife, political, dynasty Severa. 


\section{Introducción}

Considero necesario realizar una breve introducción para que conozcamos la situación política y cronológica por la cual estaba pasando el Imperio Romano en la época en la cual se produce la llegada de Julia Domna al poder.

Nuestra protagonista será la primera emperatriz que pertenezca a la dinastía de los Severos. Esta dinastía había surgido bajo el mando de su marido Septimio Severo, el cual, a pesar de no pertenecer a la familia imperial, logró entrar en el ejército e ir ascendiendo hasta hacerse con la púrpura. El ascenso al trono de Septimio Severo se produjo tras una guerra civil que se produce a la muerte de Pertinax. Debido a las reformas que este emperador quería imponer en el ejército, fue asesinado en apenas tres meses después de su coronación. Tras varias convulsiones, los pretorianos optaron por nombrar emperador a Didio Juliano, el cual no fue aceptado ni por el Senado ni por el pueblo de Roma. Al poco tiempo de estar instalado en el trono, los soldados aclaman imperator a Septimio Severo que se encontraba luchando en la Panonia Superior (actual Austria), por lo que emprendió el camino de regreso a Roma donde al mismo tiempo Didio Juliano era asesinado. Una vez reconocido emperador por el Senado debió luchar contra el resto de adversarios (Clodio Albino y Cayo Pescennio) que el ejército también había aclamado.

Finalmente logró restablecer el orden y dar unidad al Imperio, creado así una dinastía con rasgos propios que intentaría conectar con la anterior dinastía Antonina. Es entre todos estos entresijos en los que se encuentra enmarcada Julia Domna, a la cual vamos a acércanos a través de las fuentes del momento (algunas como Historia Augusta, Herodiano o Dion Casio bastante tendenciosas) y que iremos contrastando con la información obtenida de recientes estudios.

\section{Origen y ascenso al trono imperial}

Los datos que mejor conocemos de la vida de Julia Domna se enmarcan bajo figuras masculinas de la talla de su esposo Septimio Severo o su primogénito Marco Aurelio Antonino, más conocido como Caracalla. Es imposible hablar de la vida de esta mujer pasando por alto a estos emperadores (Comucci, 1987) puesto que le tocó convivir bajo la presencia de ambos. Septimio Severo, alrededor del 176, había contraído matrimonio con Marcia, calificada como una mujer sencilla y de la que pronto quedó viudo (Dávila, 2004). El futuro emperador Septimio Severo había tenido varias visiones que le anunciaban su ascenso al trono imperial. En estos oráculos, aunque llegase a ser su esposa y fiel ayudante, Julia aún no aparece. Será durante una consulta a su horóscopo en África, cuando Julia aparezca como garante de su encumbramiento imperial:

Como deseaba casarse de nuevo, al haber perdido a su esposa, se informaba del horóscopo de las prometidas...y, cuando oyó que había una mujer en Siria con un horóscopo tal, que la destinaba a casarse con un rey, la pidió por esposa y se desposo con ella gracias a la mediación de sus amigos. Esta le hizo padre enseguida.

(Historia Augusta, X, 3; 9)

Tras otra visión, en el 187 escoge a Julia Domna para casarse con ella. En estos momentos, Julia sería una muchacha de no más de 15 años y Septimio Severo un varón de 40 . Según Birley (2012) para la realización de dicho matrimonio, fue de vital importancia el papel llevado a cabo por los comerciantes sirios asentados en las orillas del Ródano, pues, parece ser que fueron éstos quienes llevaron a Julia la carta en la cual el emperador pedía su mano. Dicha carta llegaría a Siria alrededor del 187, año en el que debió de celebrarse el matrimonio de la pareja (Birley, 2012). Para tal acontecimiento, Julia llegaría a Roma acompañada de su hermana, Julia Maesa y de sus dos sobrinas, Soemias y Mamea, las cuales más adelante continuarán teniendo un papel preponderante 
en la Domus Augustea.

Julia Domna que vivió entre 170- 217, es según Dávila (2004, p. 225) "la primera de una serie de mujeres orientales de cultura griega que toma asiento en el palacio imperial y gobierna el Estado y Roma". Julia Domna pertenecía a una poderosa familia sacerdotal, su padre Basiano era Sumo Sacerdote del dios Sol en Emesa (actual Homs). En sus orígenes, esta mujer respondía al nombre de Martha - teoría que no está aún muy clara - nombre que fue cambiado al pasar a formar parte de la familia imperial, por el de Julia Domina. De ahí su nombre de Domna y el de lulia, como método de romanización. A diferencia de Dávila, Birley (2012) alega que Domna es un nombre de origen semítico, siendo un diminutivo arcaico de Dimna, que en árabe está relacionado con el color negro.

Birley (2012) hace un recorrido por los orígenes del linaje al que pertenece la familia de la esposa del futuro emperador, hasta llegar a Julia. Según sus investigaciones, la familia de Julia procedería de sangre real - teoría que también sostiene Comucci (1987) - a pesar de que su padre ejerciera el cargo de sacerdote de El-Gabal (Dios sirio solar y de la montaña, que fue introducido en Roma bajo el mandato del emperador Marco Aurelio Antonino, como consecuencia de su antigua vida como Sumo sacerdote del dios). Sin embargo, para Dión Casio la familia de Julia no tenía nada de sangre real, sino que afirma que esta mujer "había surgido del pueblo" (Dión Casio, LXXIX, 24). Puede ser que la información de Dión Casio formase parte de una estrategia para desprestigiar o no tomar en serio la labor llevada a cabo por esta mujer, pero ¿Por qué? A lo largo de este trabajo conoceremos la labor desempeñada por esta mujer y cómo contrastaba con la sociedad romana del momento.

\section{Claroscuros familiares}

Birley (2012) da la razón a Elio Esparciano - uno de los autores a los que la tradición le atribuye la participación en la escritura de Historia Augusta - acerca del nombre del primogénito de Julia. El niño fue llamado Basiano - Marco Aurelio Antonino - cognomen que pertenecía al padre de Julia. Un año después de su primogénito, en 189, nacería su segundo hijo, el cual fue llamado Septimio Geta. Según Dávila (2004), Marco Aurelio Antonino sería hijo de Julia - afirmación que se apoya en el hecho de que el padre de Julia se llamara al igual que el niño, Basiano, por lo que la madre había logrado conseguir transmitir su filiación materna, hecho poco extendido en la Antigua Roma y que difiere de la idea aportada por Elio Esparciano en Historia Augusta. Ésta última fuente afirma que Marco Aurelio Antonino llevará a cabo el asesinato de su hermano Geta. Parece que Marco Aurelio Antonino, "al ver llorar a la madre de Geta y a otras mujeres después de la muerte de su hermano, intentó darles muerte, pero se abstuvo de ello por no aumentar la reputación de crueldad que le había acarreado su fratricidio" (Historia Augusta, XIII, 3; 3-4). Aun así, Julia, habiendo perdido a su hijo Geta en manos de Marco Aurelio Antonino, llegó a tentarlo y casarse con él, según la obra Historia Augusta:

Interesa saber cómo dicen que se celebró el matrimonio con su madrastra Julia. Dicen que un día que esta bellísima mujer se presentó casi completamente desnuda, simulando que se trataba de un descuido, Antonino, la dijo; "Te querría si fuera lícito», ella le replicó diciendo: «Si quieres, es lícito. O ¿acaso no sabes que tú eres emperador, y que tú das las leyes y no las recibes?». Al oír esto, su pasión desordenada se vio azuzada a cometer el crimen y celebró unas bodas que él más que nadie debería haber prohibido, si hubiera sido consciente de que era él a quien le competía legislar. Tomó pues, como esposa a su madre (a la que no se le debería llamar con otro nombre) y sumó a su fratricidio un incesto, ya que se unió en matrimonio a aquélla a cuyo hijo había asesinado poco antes.

(Historia Augusta, XIII, 10; 2-5)

Elio Esparciano cuenta cómo tras un sueño en el que el emperador Septimio Severo descubre

Panta Rei (2014), 25 - 37 
que su sucesor sería un Antonino. Como parte de su política de legitimización, añadió el nombre de Antonino a su primogénito, Marco Aurelio Antonino, haciéndolo así heredero de su gobierno y del legado de los Antoninos. Aunque más tarde, "siguiendo los consejos que le dictaba su condición de padre o, como dicen otros, amonestado por su esposa Julia" (Historia Augusta, XIV, 1; 5) también reconoció este nombre para su hijo Geta, para evitar que quedase apartado del trono.

También debemos dar gracias a Elio Esparciano por trasmitirnos un episodio que ocurrió tras el nacimiento de Geta. Parece ser que el mismo día del alumbramiento del pequeño, una gallina puso un huevo de color púrpura que le fue llevado a Marco Aurelio Antonino, el cual lo rompió estrellándolo contra el suelo. Con lo que Julia respondió diciendo; "Maldito fratricida, acabas de matar a tu hermano" (Historia Augusta, XIV, 3; 3). Esta frase que Julia había lanzado a modo de graciosa ocurrencia, Septimio Severo la tomó como un augurio de lo que pasaría años después. Algunos de los presentes en el patio del corral, aseguraron que "Julia había hablado impulsada por una fuerza divina" (Historia Augusta, XIV, 3; 4).

Aunque no fuese su primera esposa, lo cierto es que el título de matrona o de mater familiae, fue usado por Julia Domna para potenciar su imagen como primera mujer del Estado. Estos títulos constituyen un símbolo de esposa y mujer de buenas costumbres, es decir, "aquella que no ejerce oficio liberal alguno, como ser actriz, sirvienta de taberna o prostituta" (Bailón, 2010, p. 501). Sin embargo, Herodiano nos dice que Marco Aurelio Antonino debía de soportar las burlas que hacian sobre él y sobre "su vieja madre, a la que llamaban Yocasta" (Herodiano, IV 9; 3 ) un insulto en la época, puesto que no solo se refería a la rivalidad que existía entre los hijos de Yocasta (antigua reina de Tebas, que terminó casándose con su hijo Edipo, tras el asesinato de su esposo a manos de su hijo) sino también se refería a la relación incestuosa que se presuponía que existían entre ella y Marco Aurelio Antonino. Herodiano da gran importancia a este hecho, dejando vislumbrar lo duro que era para Marco Aurelio Antonino tener que soportar las burlas que hacían sobre él y sobre su madre. En el estado de la cuestión no sabemos si dichas críticas estaban fundamentadas o simplemente se valían de las habladurías de la época para desprestigiar la figura de la emperatriz, la cual contaba con varios animadversarios.

\section{Ludi en la política}

Julia Domna aparece abundantemente representada en la numismática y con distintas concepciones, incluso apareciendo en las monedas sentada en el trono de Juno, diosa que en la mitología romana no solo protege a las mujeres, sino que también esta asimilada con el Estado, siendo la mujer de Júpiter. Según la numismática y una inscripción de Palermo, en el 193 será proclamada Augusta. En Grecia, será conocida como «salvadora de los atenienses», llegando a realizarse una estatua suya en el templo de Atenea Polias y también en el Partenón, incluso organizando sacrificios en su honor. El 14 de abril de 196, como consecuencia de su presencia en el campamento (sobre la presencia de Julia en los campamentos militares, junto a su esposo e hijos, consultar: Levick, 2007, cap. III, p. 33-56, en este capítulo realiza una interesante recogida de fechas y lugares a los que la emperatriz viajó como consecuencia de las campañas militares desarrolladas) será nombrada como mater castrorum, título que se le otorga en modo de agradecimiento a su participación para logar la victoria de las tropas sobre Osroene (campaña explicada en Levick, 2007, p. 42). Con este título las tropas pasaban a estar bajo la protección de la emperatriz y ésta a su vez pasaba a estar protegida por las tropas, lo que parece indicar la conexión que se quería establecer entre la familia imperial, bajo la persona de Julia Domna, y el ejército (Hidalgo de la Vega, 2012).

Por lo tanto, podemos apreciar que estamos ante una mujer que solía acompañar a su esposo en sus expediciones y que debía de tener un gran peso en las decisiones políticas (Burns, 2007). Consecuencia de esta actitud viajera, llegará a visitar ciudades como Lugdunum (lugar donde dará a luz al futuro emperador Caracalla), o lugares como Mesopotamia y países exóticos como Egipto en el 199, que en opinión de Burns (2007) la religión fue la principal razón para la realización de este viaje. También visitó Etiopía, lugar donde la emperatriz escapó de una infección que en cambio, si 
llegó a hacer enfermar al emperador (Turton, 1974). Llegará incluso a visitar las tierras de Britania, como consecuencia de las guerras en esta zona, y será durante este viaje en el 208 cuando ante las críticas de la emperatriz a la vida que llevaban las mujeres bárbaras del lugar, una de éstas le contestase "mucho mejor aplacamos nosotras los instintos de la naturaleza que vosotras, las romanas. Nosotras mantenemos relaciones abiertamente con los mejores hombres. Vosotras vivís en concubinato a escondidas con los peores" (Dión Casio, LXXVII, 17).

El año 197, el Senado nombra a Marco Aurelio Antonino Imperator destinatus, o "sucesor" y Julia Domna es aclamada como mater Caesaris, mater imperatoris destinatus. En el 198, Caracalla pasa a ser Augustus y Geta Caesar, y ella aparece como mater Augusti, Pius y Felix. Llegará incluso a recibir los títulos de mater Senatus y mater Patriae, epítetos que se acrecentarán tras la subida al trono imperial de Marco Aurelio Antonino. Tras la muerte de Geta, las dedicatorias en donde Julia aparece nombrada como "Madre de los Augustos y del ejército", se cambian por "Madre de nuestro Augusto y del ejército, y del Senado y de la Patria" (Dávila, 2004, p. 240). Todas estas distinciones consiguen que Julia Domna alcance las más altas cotas de poder al quedar relacionada honoríficamente con el ejército, el Senado y el gobierno directo del Estado (Bailón, 2010).
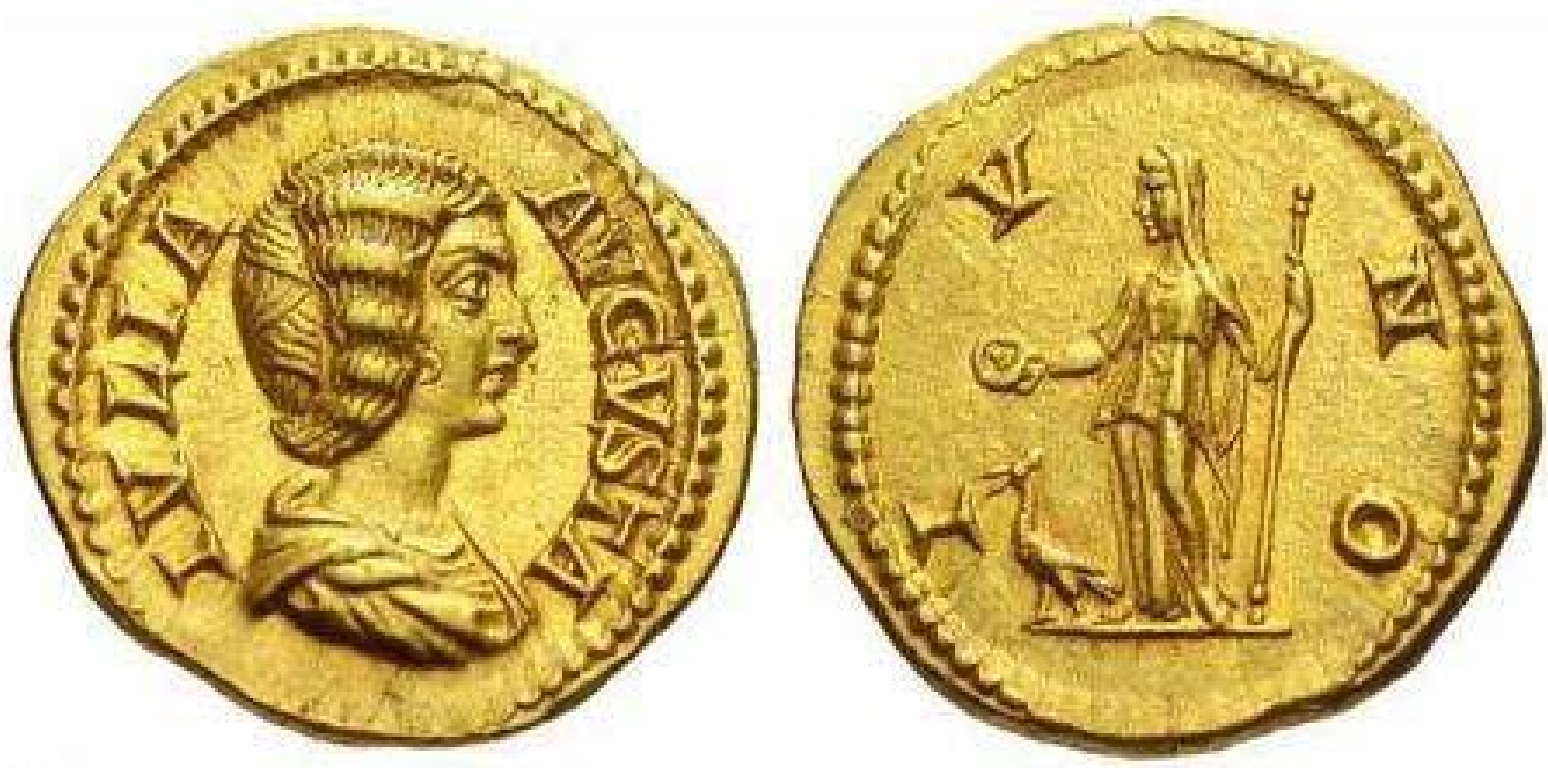

Figura 1: Áureo con el busto de Julia y la figura de Juno. Época de Septimio Severo. Fuente: Roman Imperial Coinage, 559 (cf. Sear, 6557).

Septimio Severo, a diferencia de su letalidad en el terreno político, fue más permisivo en el terreno sentimental. Para los autores antiguos, Julia "se había deshonrado por sus adulterios e incluso era cómplice de una conjura" (Historia Augusta, X, 18; 8). Sería el peor enemigo de Julia quien diese más popularidad a esta noticia, llegando, pese a la preeminencia e influencia de la emperatriz, a eclipsar su poder (Burns, 2007). Este personaje era el prefecto de la guardia $C$. Fulvius Plautianus, conocido para nosotros como Plauciano, quien según Turton (1974) era un viejo amigo desde la niñez - o al menos de una larga relación de amistad - de Septimio Severo en Leptis Magna (su ciudad natal) y el cual gobernaba en el lugar del emperador cuando éste se sentía indispuesto a causa de sus problemas con la enfermedad de la gota. Para Dión Casio, en ocasiones era Plautianus quien ejercía el poder del emperador, quedado la emperatriz relegada y vejada. Las palabras de Dión Casio son las siguientes: 
En gran medida Plautianus, tenía el dominio en todos los sentidos sobre el emperador, incluso a menudo él trata a Julia Augusta de manera escandalosa. Plautianus la detestaba y siempre la acusaba violentamente ante Severo. Llevó a cabo investigaciones para reunir pruebas en su contra, para ello usaba torturas incluso con damas nobles. Por esta razón empezó a estudiar filosofía y a pasar sus días en compañía de los sofistas.

(Dión Casio, LXXVI, 3)

El relato de Dión Casio continúa con la descripción de todos los vicios a los que Plautianus se entregó. El nivel de conjuras, engaños y desgaste es tal que en los "últimos meses de reinado de Septimio Severo, Caracalla, Geta y Julia Domna pasarán a primera línea alcanzando un máximo relieve. Tres actores y un drama con un objetivo: controlar el imperio" (Saavedra-Guerrero 2007, p.121). Tras la muerte de Septimio Severo, dejando como sucesores a sus dos hijos legítimos (Basiano y Geta, los cuales se odiaban) Julia tendrá el papel de mediar entre los hermanos y el Senado. Las fuentes nos trasmiten la idea con la cual se habría podido conseguir obtener la paz entre los hermanos, llevando a cabo un Doble Principado dividiendo el Imperio; la parte oriental y helenística para Geta, mientras que Basiano, mencionado por Herodiano como Antonino, obtendría los territorios occidentales, incluida Roma. Este hecho lo recoge bien Herodiano:

Antonino...salió del territorio de los bárbaros y corrió a encontrarse con su hermano y con su madre. Cuando estuvieron juntos, su madre intentó reconciliarlos... al encontrarse con una total oposición a su propósito, Antonino, más por necesidad que por convencimiento, acabó por aceptar la concordia y una amistad más fingida que verdadera. Así los dos se hicieron cargo del gobierno del imperio con igual poder.

(Herodiano, III 15, 6)

En opinión de Gibbon (2006, p. 130) "los emperadores solo se juntaban en público y ante la presencia de su desconsolada madre". A pesar de todo, Julia, consiguió parar momentáneamente las rencillas y parar el reparto del Imperio:

Habéis hallado, hijos míos, el medio de repartir la tierra y el mar, y es cierto que el Ponto separa los continentes. ¿Pero cómo ibais a repartir a vuestra madre? ¿Y, cómo mísera de mí, sería repartida y distribuida a cada uno de vosotros? Matadme, como es natural, primero, y que cada uno separe su parte y la entierre en su territorio. Así, también yo sería repartida entre vosotros, lo mismo que la tierra y el mar.

(Herodiano, IV 3, 4-9)

Según Herodiano, con estas palabras Julia consiguió que los hermanos recapacitaran y el proyecto de división territorial se pospusiera, hasta la muerte de Teodosio. Sin embargo, la paz no duraría mucho tiempo. Dión Casio (LXXVIII, 2) nos dice que "Antonino quiso matar a su hermano en las Saturnalia, pero no pudo hacerlo, porque su propósito malvado se había convertido ya demasiado evidente para permanecer oculto". A partir de ahora los encuentros entre los hermanos serán más violentos, llegando ambos a tomar medidas defensivas por miedo a posibles conspiraciones por parte del otro hermano. Finalmente, a finales del 212 Marco Aurelio Antonino visitará el palacio de Julia en donde asesinará a su hermano Geta, el cual morirá pidiendo auxilio en los brazos de su madre.

Por la información que nos da Dión Casio, parece que Marco Aurelio Antonino había convencido a Julia para que lo reuniese con su hermano a solas, con el objetivo de poner fin a su mala relación. Geta aceptó esta proposición y así fue como unos soldados, según Dión Casio (LXXVIII, 2) instruidos por Marco Aurelio Antonino, acabaron con la vida de Geta. Tras este suceso, Julia debió de esconder su dolor, recomponerse rápidamente y apoyar la inocencia del emperador para influenciarlo y seguir 
tomando decisiones a su vera. Tras estos hechos, autores como Herodiano (IV 9, 3) y obras como Historia Augusta (X, 21; 7) afirman que Julia contrajo matrimonio con su hijo Marco Aurelio Antonino.

En el 212 Marco Aurelio Antonino, conocido también como Caracalla, promulgará la Constitutio Antoniniana de civitate, por la cual concedía a todos los habitantes libres del imperio la ciudadanía romana y Julia quedaría al frente del Consilium Principis. Parece que Marco Aurelio Antonino se desinteresó por la gestión de los Asuntos de Estado confiándoselos a este organismo, formado por intelectuales y juristas destacados, a cuyo frente se hallaba la propia Julia Domna (Bailón, 2010). Es a partir del 214-216 cuando la emperatriz decide alejarse de los campamentos del ejército para pasar a ocuparse solamente de los asuntos políticos, quedando Marco Aurelio Antonino al frente de los asuntos concernientes al estamento militar. Muestra de este hecho se conservan cartas enviadas por el emperador, desde sus campañas en Germania, Tracia o Asia Menor, a la emperatriz. Para Turton (1974), Julia desde su regreso de Britania había estado viviendo en la capital imperial, atendiendo los asuntos de estado que su hijo había dejado en sus manos. Con esta medida, Marco Aurelio Antonino "evitaba que una gran cantidad de cartas sin importancia se le enviasen a él mientras se encontraba en el país enemigo" (Dion Casio, LXXVIX, 4).

Tras el asesinato de Caracalla en el 217, Casio afirma que las intenciones de Julia eran aglutinar a todos sus opositores bajo un solo frente y seguir ella manejando el poder. Sin embargo, la idea de Julia no se pudo realizar, siendo su conjura contra Macrino descubierta y obligada a abandonar Antioquía, lugar donde, según Levick (2007) había pasado largos periodos de su vida. Un fragmento bastante dañado, que nos ha trasmitido Casio (LXXVIX, 23) dice que fue obligada a volver a su país natal, hecho que no parece que se llegase a realizar. Lo que sí está comprobado es que en estas circunstancias, Julia se retiró del poder, recluyéndose en su palacio de Antioquía - ciudad que no quiso abandonar pese a las órdenes del nuevo emperador - y terminando sus días lejos de la grandeza de la que había estado acostumbrada toda su vida, una situación que recoge bien Gibbon cuando dice:

A pesar de la comedida atención que expresó el usurpador hacia la viuda de Severo, ésta descendió de manera dolorosa a la condición de súbdita y con el suicidio se liberó de tan congojosa humillación.

(Gibbon, 2006, p. 136)

Coindicen las fuentes al decir que en el 217, ella misma decidió dejarse morir de inanición, aunque Herodiano nos dice que murió en extrañas circunstancias parecidas a un suicidio, pero "no sabemos si lo hizo voluntariamente o forzada por una orden" (Herodiano, IV, 1; 38). Casio (LXXIX, 24) menciona que desde hacía mucho tiempo padecía un cáncer de mama, que se habría visto aumentado como consecuencia del golpe que llevó con el asesinato de su hijo. Este mismo autor nos dice que tras su muerte, su cuerpo fue "llevado a Roma y enterrado en la tumba de Caius y Lucius" (Dión Casio, LXXIX, 24).

\section{Influencia en el ámbito cultural}

Desde niña Julia Domna había recibido una educación acorde a su sexo, sin embargo, pertenecía a la aristocracia de Emesa y como expone Levick (2007) es obvio que su educación hubiese sido la mejor. En este lugar había una mezcla de culturas oriental y griega, lo que hará que existan diferencias con respecto a la educación de las féminas romanas. Tras su llegada a Roma como nueva emperatriz los miembros de la dinastía - de la que ahora ella formaba parte aparecerán representados juntos, bajo paralelos estilográficos del Oriente, no existiendo a priori paralelos en el ámbito romano. Ahora será muy significativa la iconografía asociada al trono de Septimio, pasando los retratos de la familia imperial a formar el ideal de la familia romana tradicional y noble (Bailón 2010; Comucci, 1987).

Como consecuencia de su influencia, tras ser acusada de adulterio se retirará dos años a

Panta Rei (2014), 25 - 37 
la vida contemplativa y filosófica, reapareciendo tras la muerte de su archienemigo. A pesar de esta momentánea desaparición, en el año 204 Septimio Severo organizará unos Ludi Saeculares, que consistían en unas fiestas religiosas de tres días y tres noches, durante las cuales no solo se realizaban sacrificios sino también representaciones teatrales para conmemorar un aniversario, normalmente de cien años en cien años. Coincidiendo con estos juegos seculares, Julia afianzará su influencia sobre su marido (Burns, 2007). Es en esta ocasión, cuando por primera vez participará una mujer en los juegos, Julia, consiguiendo el calificativo de Augusta. También aparecerá representada en los frisos y relieves que se levanten en honor el emperador (Comucci, 1987) como es el caso del arco de Leptis, en donde Julia se encuentra en el centro de la escena junto a los dioses, exaltando así el ideal romano de maternidad y de la dinastía divina. En la parte sudeste de este mismo friso, la emperatriz aparece como una Victoria, con una palma en la mano, tras Hércules y delante de la cuadriga (Dávila, 2004).

Julia Domna llegó incluso a ser comparada con Aspasia (Flavio Filostrato, Vida de los Sofistas, 622) y tomó atribuciones hasta entonces solo reservadas al emperador (Levick, 2007) como por ejemplo apoyar como profesor de Atenas al sofista Filisco de Tesalia, (Comucci, 1987; Levick, 2007) manteniéndolo incluso durante siete años después de haber caído en desgracia bajo el mandato de Caracalla. Flavio Filostrato se refiere a ella como una dama con aficiones filosóficas, la cual se rodeaba de un círculo de personas notables dentro el ámbito del conocimiento, información que deja plasmada en este pasaje "marchó Filisco a Roma para solventar su asunto, se aproximó a los matemáticos y filósofos que rodeaban a Julia y consiguió de ésta, por nombramiento imperial, la cátedra de retórica de Atenas" (Flavio Filostrato, Vida de los Sofistas, 622).

Esta emperatriz, fue la primera mujer que volvió a estudiar retórica desde época de los Graco (Hidalgo de la Vega, 2012) y en opinión de Turton (1974) con la desaparición de Julia se llevaría a cabo el ocaso de las artes y las ciencias. Hasta ese momento, la presencia, interés e integración de Julia Domna en el mundo de las artes y sabiduría podemos encontrarla en fragmentos como el siguiente:

Un pariente de Damis puso en conocimiento de la emperatriz Julia las tablillas de estas memorias, hasta entonces desconocidas. Y a mí, que pertenecía a su círculo (puesto que ella elogiaba y admiraba todos los discursos retóricos) me encargó que volviera a redactar estos ensayos y me ocupara de su publicación...

(Flavio Filostrato, Vida de Apolonio de Tiana, I; 3)

En el plano religioso, debemos apuntar que fue asimilada a un buen número de divinidades como Deméter, Hera, Cibeles y la africana Juno Celeste. Igualmente, Turton (1974) afirma que la emperatriz incluso rezó a su dios Sol sirio para conseguir la victoria de su esposo en Mesopotamia. Esta orientalización que el Imperio había comenzado bajo la figura de Septimio Severo y Julia Domna, en opinión de Dávila (2004) se verá acrecentada bajo el mandato de Marco Aurelio Antonino, debido sobre todo a la influencia de Julia. En el 213, la Corporación de los Hermanos Arvales (una Cofradía formada por doce flamines, cuyo origen se remonta a época arcaica y cuya duración se prolongó en el tiempo hasta la definitiva implantación del cristianismo) propició alabanzas al emperador y por primera vez a una emperatriz, tales como " $i B r a v o$ Julia Augusta, madre de Augusto! Gracias a ti, Augusta, dirigimos nuestra mirada a Augusto. ¡Que Dios os proteja a los dos por siempre, oh Augusto, oh Augusta!" (Dávila, 2004, p. 247).

Bajo el mandato de Marco Aurelio Antonino también se la seguirá representando en las monedas. Su efigie queda inmortalizada en los dobles denarios (podemos encontrar una síntesis de los epítetos referidos a Julia Domna aparecidos en la numismática en Lusnia, 1995, p.119140) que en el 214 son puestos en circulación. A diferencia de su anterior época, en la cual era representada como madre virtuosa y asimilada a Juno, ahora se la representará con dotes divinas del Sol y la Luna. También en la numismática queda reflejada la introducción de cultos orientales, con la iconografía de toros, serpientes o leones. 
La Dinastía Severa, sería la primera en acuñar monedas para todas las mujeres de la familia; esposas, madres y abuelas. En unas monedas acuñadas con motivo de la conmemoración del adventus del emperador, aparece la pareja imperial y en el reverso de las monedas se expresa la esperanza y buen gobierno del que disfrutaba la sociedad (Hidalgo de la Vega, 2012). De esta manera, para Bailón (2010) la emperatriz queda constituida como máxima representante femenina del Estado, atribuyéndose todas las virtudes que debe poseer la primera mujer del Imperio.
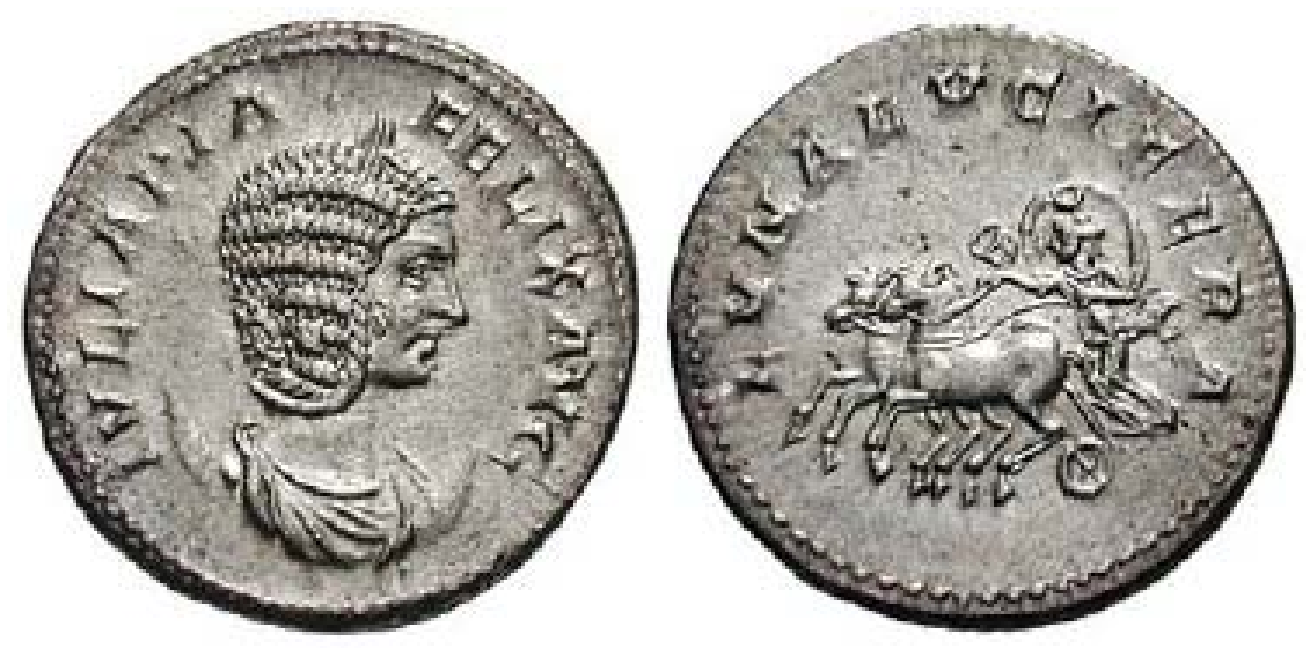

Figura 2: Denario con el busto de Julia y la Luna. Época de Basiano. Fuente: Roman Imperial Coinage, RIC 379a.

Son muy significativos los adjetivos con los que aparece Julia en el anverso de la moneda anterior (PIA, FELIX, AVG) y la iconografía seleccionada para el reverso, siendo según los estudiosos, la Luna el auriga de los caballos para el combate. El uso de la Luna tiene su sentido si lo contraponemos al Sol, que era el emperador. También tenemos que tener en cuenta que la Luna se asemejaba a la diosa Tanit o la Astarte oriental, cuyo culto había sido introducido por Septimio Severo en el Imperio y en dónde la toma de esta decisión la palabra de Julia no estaría muy en desacuerdo (Magnani, 2008). Aunque su presencia en el campo cultural le sirva a Julia para demostrar y fijar su poder, en opinión de Saavedra-Guerrero (2009) Julia se sirve del arte y la numismática para transmitir solidez, estabilidad y continuidad por los confines del Imperio.

\section{Belleza y astucia: sincretismo con la Luna}

Su continua actividad y firmeza es comentada por Casio, quien afirma que "el emperador poseía la astucia de su madre y de los sirios" (Dión Casio, LXXVIII, 10). De igual modo, para Dávila (2004) Flavio Filostrato alaba la inteligencia de esta mujer. De hecho, su carta número LXXIII va dirigida a la emperatriz, a la cual nombra como "la filósofa" lo que es un extraño adjetivo para una mujer de su tiempo. Todos los autores coinciden al hablar de los rasgos físicos de la emperatriz, calificándola de bella y atractiva. Llega a ser considerada una gran matrona perteneciente real la cual actuará de una manera muy activa, teniendo una imagen pública muy poderosa (Hidalgo de la Vega, 2012). Aunque no es una fuente directa, no podemos pasar por alto la clara descripción de todas las cualidades y aptitudes de la emperatriz realizada por Gibbon:

Julia Domna era merecedora de cuanto le prometía su signo. Poseía, aún en edad muy madura, el embeleso de su hermosura, y hermanaba la viveza de su imaginación con la entereza y el tino que raramente realzan su sexo. Sus amables cualidades no hicieron ninguna mella en su celoso marido, pero durante el reinado de su hijo manejo los negocios de mayor monta con tal cordura que sostuvo su autoridad. Y con tanta 
moderación que solía refrenar sus ímpetus más bravíos. Julia también se dedicó al estudio de la filosofía con beneficio y prestigio, pues patrocinaba todas las artes y agasajaba a los talentos. Los sabios, agradecidos, han aclamado elogiosamente sus virtudes, pero si damos crédito a las habladurías de la historia antigua, la castidad no fue por cierto la virtud más eminente de la emperatriz Julia.

(Gibbon, 2006, p. 127)

Los retratos de Julia Domna, pasarán de unos aspectos y facciones más genéricas a unos rasgos cada vez más específicos, lo que para Burns (2007) puede ser una manera de emparentarse con la dinastía Antonina que tan presente estaba en la memoria de su esposo Severo. En las esculturas aparece peinada con ondas en la parte superior que terminan recogiéndose en trenzas anudadas en un moño, esto es considerado por algunos artistas como un peinado de características sirias. A partir de entonces se pone de moda la ondulación, ahora el moño disminuirá de tamaño a favor de las ondas que cada vez serán más amplias (Burns, 2007). La influencia de esta mujer no solo se dejará notar en el arte suntuario, sino que también se verá reflejada en los cultos religiosos y en el carácter orientalizante que comienza a predominar en el Imperio, en detrimento de la latinidad llegando el latín a convertirse una "lengua extraña" según Dávila (2004, p. 227). Sin embargo, para Hidalgo de la Vega (2012) el oriente griego de esta época ha conseguido un grado de romanización muy importante, llegando el latín - importado por los soldados romanos y los propios mercenarios de la zona que pasaban a nutrir las filas - a tomar gran poder frente a las distintas lenguas que se hablaban. Durante los años de apogeo del gobierno de su marido Septimio Severo, la influencia y presencia de Julia en la mayoría de sus viajes y actividades políticas era considerable. Con su influencia incluso consiguió que el emperador permitiese a los soldados casarse y vivir con sus mujeres e hijos (Burns, 2007). Se pone en el centro del movimiento intelectual y religioso, expresión del sincretismo dominante en la época (Comucci, 1987). Es una mujer atenta a los cambios de su época, que conoce bien la atmósfera que se respira. Por su carácter se la identificaba con la diosa de la sabiduría y de la guerra, características que quedarán representadas en la numismática, como ya hemos visto anteriormente (Dávila, 2004).

\section{Reflexiones finales}

Tras conocer las peripecias que llegó a vivir Julia Domna, nos viene la imagen de una mujer astuta y muy inteligente, que supo mantenerse en la primera línea del poder, al lado de los cuatro varones más influyentes del momento y a los cuales sobrevivió, tres de ellos de su familia y uno su enemigo y mayor detractor Plauciano, llegando a influenciarlos con sus ideas y por qué no, incluso a manejarlos. Sin embargo, estas características unidas a la frivolidad con que resurge tras el asesinato de su hijo Geta, y su posterior posicionamiento al lado del asesino, llegan a vislumbrar atisbos de una mujer sin escrúpulos, en donde lo único que realmente le interesa es el poder. Aunque deberíamos pensar que no tenía otra oportunidad, si quería seguir conservando su vida, en una sociedad regida por varones.

Si algo queda claro es que con la dinastía sirio-africana que formarán Septimio Severo y Julia Domna, se producirá una coyuntura en las tradiciones romanas y se introducirán nuevas tradiciones de corte oriental. Seguramente, la influencia que ejercía la familia de Julia en aquellos momentos debía de ser bastante considerable. Esto, unido al formidable carácter de la futura emperatriz, era la combinación perfecta para que Septimio Severo se consolidase en el poder. Si somos capaces de olvidarnos solo por un momento de su estatus social y político, está mujer llegó a ser acusada adulterio y de conspiración contra su propio marido - el cual era a parte, el mismo emperador - y como tal debería de haber sido castigada. A pesar de las graves acusaciones, Julia logró conservar la vida lo que nos hace pensar en varias hipótesis:

- Probablemente no se pudiera comprobar la veracidad de tales acusaciones. 
- Disfrutaba de tal poder y de manipulación sobre el emperador, que Septimio Severo no pudo arrebatarle la vida.

- Todo fue un invento de su enemigo Plautianus, para desprestigiarla y quitarse así una dura contrincante por el poder durante las indisposiciones de Septimio Severo.

Afirmar con rotundidad alguna de estas hipótesis nos haría caer en un falso histórico, puesto que no podemos demostrar tales ideas. En cambio, al observar la ejecución y obra de esta emperatriz, vemos como bajo las vestiduras de una mujer se escondía un carácter prototipo de los varones. En el caso de la figura de Marco Aurelio Antonino da la sensación de que es ella la que está por encima del emperador. Ambición por el poder y altas miras para conservarlo, a pesar de los obstáculos y prejuicios que la sociedad romana tenía ante la idea de una mujer fuerte y capaz de gobernar, hacen posible que llegase a plantearse un matrimonio-regencia durante el tiempo que dura el gobierno de Caracalla. Uso este término ya que si es cierto que Caracalla era realmente hijo de Julia, el matrimonio probablemente no se habría consumado como tal. Estaríamos entonces hablando de un matrimonio meramente formal y político, por intereses para ambos. En el caso de que este matrimonio llegase a darse en realidad, nos hace pensar en una acción de legitimación por parte de Marco Aurelio Antonino y que se enmarcaría dentro de un contexto de intrigas palaciales por el poder.

Vemos como la figura de Julia es sin lugar a dudas un referente para su época. Una época en donde la mujer que se salía de los límites convencionales marcados, no estaba bien vista. Julia no sólo intentó mantener todas sus virtudes como mujer tradicional romana, al cuidado de su esposo e hijos sino que como mujer helénica-oriental, siguió manteniendo el contacto con la filosofía y demás ciencias. Esta enérgica actividad, nos descubre a una mujer con carácter, sensata y al mismo tiempo sentimental y maternalista, que pese a las adversidades consigue situarse en un lugar privilegiado desde donde ejercer de facto un auténtico poder. Es una figura femenina que ya entre sus contemporáneos debió de llamar la atención, tanto que, aún seguimos hablando e investigando sobre ella.

\section{Bibliografía}

Abraham, R. J. (2009). Magic and religious authority in Philostratus. The life of Apollonius of Tyana. Pennsylvania: University of Pennsylvania.

Aleixandre Blasco, A. (2005). Iulia Domna. Mater Augusti. Protai gynaikes: mujeres próximas al poder de la antigüedad. Sema V-VI, (pp. 95-116). Valencia.

Asante, M. e Ismail. S. (2010). Rediscovering the "Lost" Roman Caesar: Septimius Severus the African and Eurocentric Historiography. Journal of Black Studies, 40, 4, 608-618.

Baharal, D. (1996). Victory of Propaganda. The dynastic aspect of the Imperial propaganda of the Severi: the literary and archaeological evidence $A D$ (pp. 193 - 235). Oxford: Tempvs Reparatvum.

Baharal, D. (1992). The Portraits of Julia Domna from the years 193-211 AD and the Dynastic Propaganda of L. Septimius Severus. Latomus. Revue d'études latines, 51, 1, 110-118.

Bailón García, M. (2010). Imagen al servicio de la propaganda ideológica y política: el caso de Iulia Domna. Toga y Daga. Teoría y praxis de la política en Roma. Actas del VII Coloquio de la Asociación Interdisciplinar de Estudios Romanos (pp. 495-510). Madrid: Signifer Libros. Barnes, T. (2012). The Family and Career of Septimius Severus. Zeitschrift für Alte Geschichte, 16/1, 87-107.

Barnes, T. (1972). Some Persons in the Historia Augusta. Phoenix, 26/2, 140-182.

Barnes, T. (1984). The Composition of Cassius Dio's "Roman History". Phoenix, 38/3, 240-255.

Barnes, T. (2008). Aspects of the Severan Empire. Part I: Severus as a New Augustus. New England Classical Journal, 35/4, 251-267.

Bartman, E. (2001). Hair and Aritifice of Roman Famele Adornment. American Journal of Archeology, $105 / 1,1-25$. 
Benario, H. W. (1958). Julia Domna mater, senatus et patriae. Phoenix, V, 12-13.

Bengoochea Jove, M. ${ }^{a}$ C. (1998). La historia de la mujer y la historia de género en la Roma Antigua. Historiografía actual. Espacio, Tiempo y Forma, Serie II. Historia Antigua, 11, 241-259.

Birley, A. R. (2012). Julia Domna. En Septimio Severo. El emperador africano (pp. 109-125). Madrid: Gredos.

Biscardi, B. M. (1987). La figura de Giulia Domna. En Donne di rango e donne di popolo nell'età dei Severi (pp. 13-28). Florencia: L.S.O.

Bowersock, G. W. (1969). Greek Shophists in the Roman Empire. Oxford: Claredon Press.

Bravo, G. (1994). La mujer romana y la historiografía moderna: cuestiones metodológicas y nuevas perspectivas de estudio. En Roles sexuales: la mujer en la historia y la cultura, (pp. 55-72). Madrid: Ediciones Clásicas.

Burns, J. (2007). Julia Domna. The philosopher. En Great Women of Imperial Rome. Mothers and Wives of the Caesars (pp. 181-205). Londres: Routledge.

Cantarella, E. (1991). La época de los Antoninos y los Severos. En La Mujer Romana (pp. 71-94). Santiago de Compostela: Universidad Santiago de Compostela.

Comucci Biscardi, B. M. (1987). La figura de Giulia Domna. En Donne di rango e donne di popolo nell'età dei Severi (pp. 13-28). Florencia: L.S.O.

Cid López, R. M. ${ }^{a}$ (1993). Las emperatrices sirias y la religión solar. Una nueva valoración. Formas de difusión de las religiones antiguas. Segundo Encuentro-Coloquio de ARYS (pp. 245-253). Madrid.

Cid López, R. M. ${ }^{a}$ (2007). Las matronas y los prodigios. Prácticas religiosas femeninas en los "márgenes" de la religión romana. Norba. Revista de Historia, 20, 11-29.

Cleve, R.L. (1988). Some male relatives of the Severan women. Historia XXXVII, 2, 196-206.

Dávila Iglesias, R. M. (2004). Julia Domna, Oriente en Occidente. En Mujeres de la Antigüedad (pp. 225-254). Madrid: Alianza.

Domínguez Arranz, A. (2009). La mujer y su papel en la continuidad del poder. lulia Augusti, ¿una mujer incómoda al régimen? En Mujeres en la Antigüedad Clásica. Género, poder y conflicto (pp. 153-183). Madrid: Sílex Ediciones.

Fernández Ardanaz, S., González Fernández, R. (2006). El consensus y la auctoritas en el acceso al poder del emperador Septimio Severo. Antigüedad y Cristianismo, XXIII, 23-37.

Ghedini, F. (1984). Giulia Domna fra Oriente ed Occidente. Le fonti archeologiche. Roma: La Fenice.

Gibbon, E. (2006). La crisis del siglo III. Guerras civiles y victoria de Severo sobre sus tres competidores. Historia de la decadencia y caída del Imperio Romano, I (pp. 111-126). Madrid: Atalanta.

Gibbon, E. (2006). La crisis del siglo III. Muerte de Severo. Tiranía de Caracalla. En Historia de la decadencia y caída del Imperio Romano, I (pp. 127- 152). Madrid: Atalanta.

González Fernández, R., Fernández Ardanaz, S. (2010). Algunas cuestiones en torno a la publicación de la Constitutio Antoniniana. Gerión, 28, 1, 157-191.

Gorrie, CH. (2004). Julia Domna's Building Patronage. Imperial family roles and the Several Revival of Moral Legislation. Historia: Zeitschrift für Alte Geschichte, 53, 1, 61-72.

Hidalgo de la Vega, M. ${ }^{a}$ J. (2000). Plotina, Sabina y las dos Faustinas: la función de las Augustas en la política imperial. Género, dominación y conflicto: la mujer en el mundo antiguo. Studia Historica, 18/1, 191-224.

Hidalgo de la Vega, M. a J. (2012). Mujeres de la Dinastía Severa. Sueños de dominio y dueñas de Roma. En Las emperatrices romanas. Sueños de púrpura y poder oculto (pp.132 -152). Salamanca: Universidad de Salamanca.

Levick, B. (2007). Julia Domna, Syrian Empress. Nueva York: Routledge.

Lusnia, S. (1995). Julia Domna's Coinage and Severan Dynastic Propaganda. Latomus: revue d'études latines, 54, 119-140.

Magnani, A. (2008). Giulia Domna. Imperatrice filosofa. Milán: Jaca Book.

Marasco, G. (1996). Giulia Domna, Caracalla e Geta: frammenti di tragedia alla corte dei Severi. 
L'Antiquité Classique, 65, 119-134.

Turton, G. (1974). The Syrian Princesses: The Woman Who Ruled Rome (AD 193-235) (pp. 115131). London: ACLS POD.

Saavedra-Guerrero, M. D. (1994). El mecenazgo femenino imperial: el caso de Julia Domna. L'Antiqué Classique, 63, 193-200.

Saavedra-Guerrero, M. D. (2006). Imagen, mito y realidad en el reinado de Septimio Severo. Julia Domna y la virtus en la familia imperial. Athenaeum. Studi di Letteratura e Storia dell'Antichicà, 1, 95-103.

Saavedra-Guerrero, M. D. (2007). El poder, el miedo y la ficción en la relación del emperador Caracalla y su madre Julia Domna. Latomus: revue d'études latines, 66, 1, 120-131.

Saavedra-Guerrero, M. D. (2009). Septimio Severo, Julia Domna y Plauciano: El juego de la traición en la domus aurea. Gerión, 27, 1, 251-261.

Sidebottom, H. (2007). Severan historiography: evidence, patterns, and arguments. En Swain, S., Harrison, S., Elsner, J. (ed.), Severan Culture (pp. 52-82). Cambridge: Cambridge.

Whitmarsh, T. (2007). Prose literature and the Severan dynasty. En Swain, S., Harrison, S., Elsner, J. (ed.), Severan Culture (29-51). Cambridge: Cambridge. 



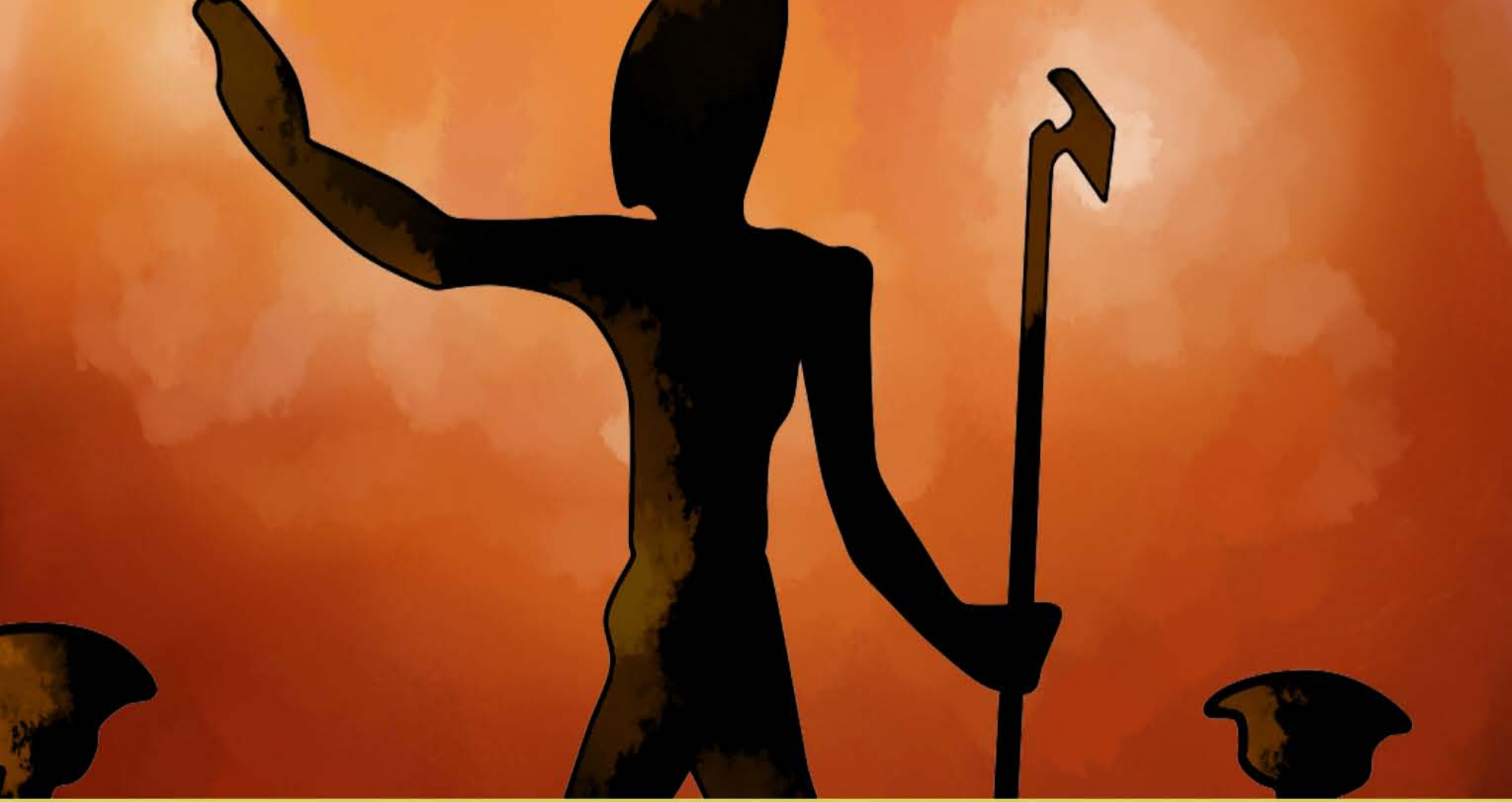

